\title{
Medical Management of Incomplete Abortion with Misoprostol -A Quasi-Experimental Study in DMCH
}

\author{
Dr. Chandana Saha ${ }^{1 *}$, Dr. Khadija Mannan ${ }^{2}$, Dr. Amatus Salam Nimni ${ }^{3}$, Dr. Farhana Rahman ${ }^{4}$, Dr. Khaledun Nessa ${ }^{5}$
}

${ }^{1-3}$ MBBS, FCPS, Junior Consultant, Dept. of Obs and Gynae, Shaheed Suhrawardy Medical College and Hospital, Dhaka

${ }^{4}$ MBBS, FCPS, Medical Officer, Dept. of Obs and Gynae, Shaheed Suhrawardy Medical College and Hospital, Dhaka

${ }^{5}$ MBBS, FCPS, Assistant Professor, Dept. of Obs and Gynae, Shaheed Suhrawardy Medical College and Hospital, Dhaka

DOI: $10.36347 /$ sjams.2020.v08i05.017

| Received: 16.04.2020 | Accepted: 24.04.2020 | Published: 14.05.2020

*Corresponding author: Dr. Chandana Saha

Objective: In this study our main goal is to describe the effectiveness of misoprostol in medical management of incomplete abortion. Method: This Quasi experimental study was done on 100 patients with incomplete abortion cases who fulfilled the inclusion and exclusion criteria were enrolled for the study at Dhaka medical college and hospital from August 2011 to January 2012. Result: During the result according to parity 32(32.0\%) patients was found primi gravida; 32(32.0\%) second gravida; $18(18.0 \%)$ third gravida, 12(12.0\%) fourth gravida, 4(4.0\%) fifth gravida and $2(2.0 \%)$ was sixth gravida. Among primi gravida $4(4.0 \%)$ patients required $1^{\text {st }}$ dose, $10(10.0 \%) 2^{\text {nd }}$ doses, $6(6.0 \%) 3^{\text {rd }}$ doses and $12(12.0 \%)$ in $4^{\text {th }}$ doses. Among multi gravida $22(22.0 \%)$ patients required $1^{\text {st }}$ dose, $20(20.0 \%) 2^{\text {nd }}$ doses, $10(10.0 \%) 3^{\text {rd }}$ doses and $12(12.0 \%)$ in $4^{\text {th }}$ doses. $65 \%$ patients strongly agreed about easy ingestion of the drug $33(33.3 \%)$ agreed and disagree $2(2.0 \%), 5 \%$ of patients strongly agreed of having discomfort after ingestion of the drug, 15\% disagreed, 30\% uncertain. Conclusion: This study concluded that misoprostol is the potential and effective drug in the medical management of incomplete abortion. Treatment with misoprostol can reduce the demand for surgical evacuation in cases of incomplete abortion. Further study is needed for better outcome.

Keywords: misoprostol, incomplete abortion, quasi experimental study.

Copyright @ 2020: This is an open-access article distributed under the terms of the Creative Commons Attribution license which permits unrestricted use, distribution, and reproduction in any medium for non-commercial use (NonCommercial, or CC-BY-NC) provided the original author and source are credited.

\section{INTRODUCTION}

In Incomplete abortion, the products of conception have partially expelled out from the uterine cavity. In gestational age of less than 10 weeks duration the fetus and placenta are usually enmesh together. After 10 weeks they may be passed separately with a portion of product retained in the uterine cavity [1].

More than fifty percent human pregnancies may be lost, although in only about fifteen percent, this is perceived as miscarriage, with lower abdominal pain and uterine bleeding being the presenting symptoms of threatened/inevitable abortion. A proportion of these unsuccessful pregnancies are now diagnosed as incomplete abortion [2]. Approximately 10 to 20 Percent of clinically recognized pregnancies fewer than 20 weeks of gestation will undergo spontaneous abortion [3]. Eighty percent of these occur in the first 12 weeks of gestation [4]. Misoprostol, a methyl-ester of $\mathrm{PGE}_{1}$, marked for prevention and treatment of peptic ulcer disease. Although it is not approved to be used in obstetric and gynecologic practice in many countries [5]. It is being very successfully used for the management of pregnancy, induction of abortion and management of 3rd stage of labour and post-partum hemorrhage in many set up, it is now considered to be a very good drug to be used in these conditions [6]. A large number of studies have shown that misoprostol is highly effective in 1 st and 2 nd trimester abortion. The most frequent side effects include nausea, vomiting, diarrhea, low grade fever, uterine hyperstimulation [7].

The appropriate misoprostol dose, route, frequency of use for medical management of incomplete abortion has not been established and debate still exists concerning misoprostol administration. So, there is an urgent need to evaluate all available information for appropriate doses and safety of the drug.

In this study our main goal is to evaluate the efficacy and safety of misoprostol in the medical management of incomplete abortion. 


\section{OBJECTIVE}

\section{General objective}

- To describe the effectiveness of misoprostol in the medical management of incomplete abortion.

\section{Specific objective}

- To detect the mean induction expulsion interval.
- To assess the cases in terms of age, parity, gestational age, socioeconomic condition.

- To find out total doses needed for complete expulsion of product of conception.

- To assess the side effects.

- To assess patient satisfaction level distribution of study patients.

\section{Methodology}

\begin{tabular}{|l|l|}
\hline Type of study & Quasi experimental study. \\
\hline Place of study & Dhaka Medical College Hospital, Dhaka \\
\hline Study period & August 2011 to January 2012 \\
\hline Study population & $\begin{array}{l}\text { Only consecutive 100 incomplete abortion cases who fulfilled the inclusion and exclusion } \\
\text { criteria were enrolled for the study. }\end{array}$ \\
\hline Sampling technique & Purposive \\
\hline
\end{tabular}

\section{Inclusion Criteria}

- Incomplete abortion cases diagnosed clinically and ultrasonographically.

- Patients who are hemodynamically stable.

- Only 1 st trimester abortion case was taken.

\section{Exclusion Criteria}

- Patient having known medical diseases.

- Patient having history of hypersensitivity to prostaglandin.

\section{METHOD}

After selecting the patient for the study, the procedure and its safety was explained to the patient and a written consent was taken. After taking detailed history and performing necessary examinations, an ultrasound was done as an integral part of diagnosing incomplete abortion. Gestational age was evaluated by last menstrual period, bimanual examination and ultrasonography. Misoprostol is available in Bangladesh as tab. cytomis $(200 \mu \mathrm{g})$, isovent $(100 \mu \mathrm{g}, 200 \mu \mathrm{g})$. After doing required investigations, $3(600$ microgram $)$ misoprostol tablets $(1 \mathrm{tab}=200 \mu \mathrm{g})$ was given orally. The dose was repeated after 6 hours if needed and maximum 4 doses were given within 24 hours.
Following administration of misoprostol, pulse, BP, temp, and systemic symptoms was monitored hourly, the patient was instructed to report cramps and vaginal bleeding initially and within 24 hours of administration of misoprostol. The patient was also instructed to report the time of expulsion of the product of conception. Patients satisfaction level was assessed with Lickert scale by 5 points

\section{Statistical Analysis}

- All relevant data for each individual patient was recorded in data collection sheet. Collected data was compiled and statistical analysis was done by using computer-based software, statistical package for social science (SPSS)

\section{RESUlT}

In table-1 shows age distribution of the study patients $(n=100)$. Where a total of 100 patients were included in this study. They were divided into five groups according to their age. 36.0\% of the patients belonged to $21-25$ years age group. The mean age was $25.34 \pm 6.43$ years with range from 16 to 45 years. The following table is given below in detail:

Table-1: Age distribution of the study patients $(n=100)$.

\begin{tabular}{|l|c|c|}
\hline \multicolumn{1}{|c|}{ Age (in years) } & Number of patients & Percentage \\
\hline$\leq 20$ & 30 & 30.0 \\
\hline $21-25$ & 36 & 36.0 \\
\hline $26-30$ & 20 & 20.0 \\
\hline $31-35$ & 8 & 8.0 \\
\hline$>35$ & 6 & 6.0 \\
\hline Mean \pm SD & 25.34 & \pm 6.43 \\
\hline Range (min-max) & $(16$ & $-45)$ \\
\hline
\end{tabular}

In figure-1 shows occupation status of the study patients where more than a half $(58.0 \%)$ patient was housewife. Garments worker was 22(22.0\%), service holder $8(8.0 \%)$, student $4(4.0 \%)$ and health assistant/visitor 4(4.0\%). The percentage of teacher and housemaid were same among the study population. The following figure is given below in detail: 


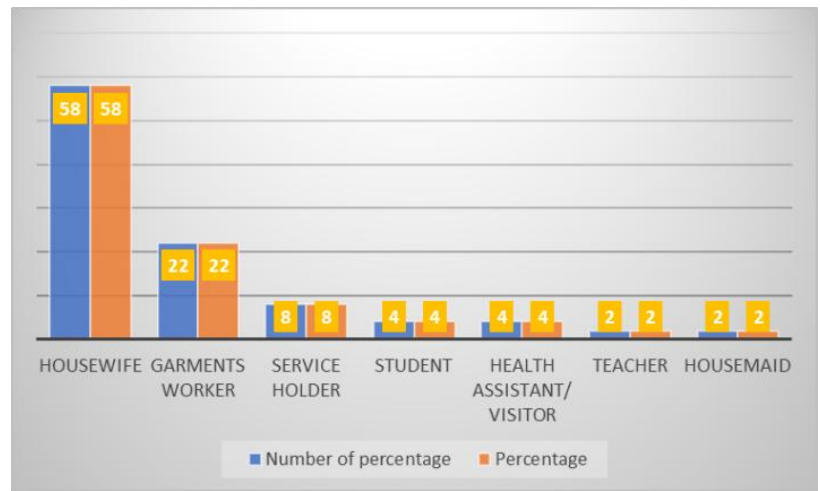

Fig-1: Occupation status of the study patients

In figure-2 shows socioeconomic condition of the study patients. Maximum 60(60.0\%) patients came from low socio-economic status, 38(38.0\%) from middle socioeconomic group and $2(2.0 \%)$ belongs to higher group. The following figure is given below in detail:

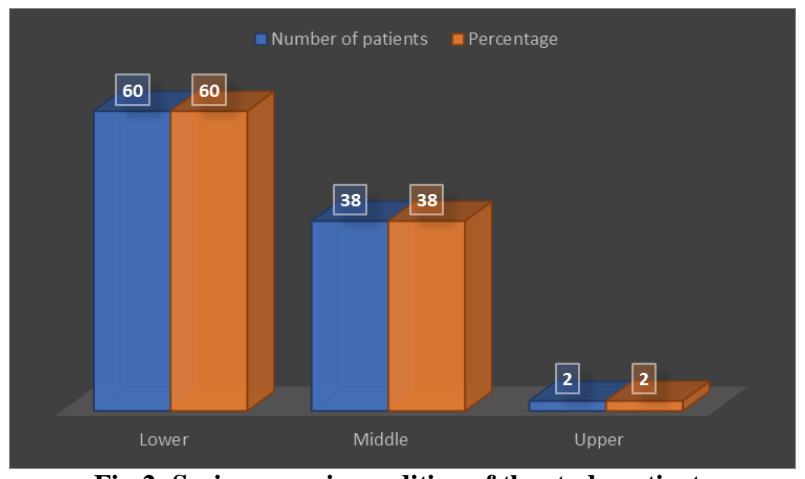

Fig-2: Socioeconomic condition of the study patients

In table-2 shows distribution of the study patients according to parity where $32(32.0 \%)$ patients was found primi gravida; $32(32.0 \%)$ second gravida;
$18(18.0 \%)$ third gravida, $12(12.0 \%)$ fourth gravida, $4(4.0 \%)$ fifth gravida and $2(2.0 \%)$ was sixth gravida. The following table is given below in detail:

Table-2: Distribution of the study patients according to parity $(n=100)$.

\begin{tabular}{|c|c|c|}
\hline Parity & Number of patients & Percentage \\
\hline 0 & 32 & 32.0 \\
\hline 1 & 32 & 32.0 \\
\hline 2 & 18 & 18.0 \\
\hline 3 & 12 & 12.0 \\
\hline 4 & 4 & 4.0 \\
\hline 5 & 2 & 2.0 \\
\hline
\end{tabular}

In figure-3 shows distribution of the study patients according to gestational age $(n=100)$. The mean gestational age was found $10.2 \pm 1.97$ weeks with range from 6 to 12 wks. The following figure is given below in detail:

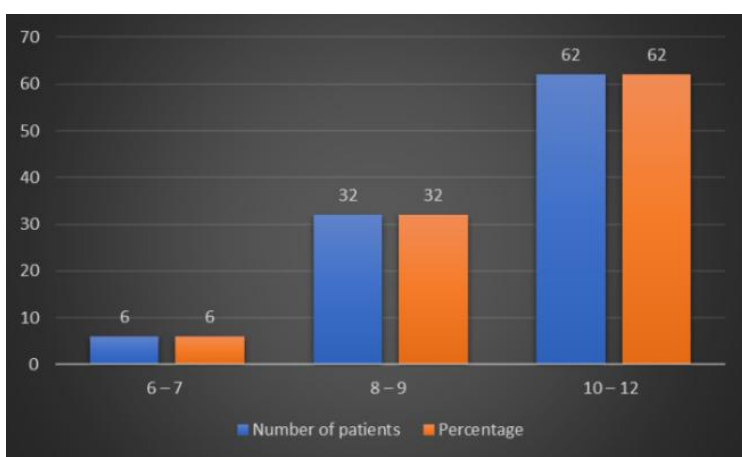

Fig-3: Distribution of the study patients according to gestational age 
In table-3 shows distribution of the study patients according to per vaginal examination findings $(\mathrm{n}=100)$. Among $\mathrm{P} / \mathrm{V}$ findings, cervical os $1.5 \mathrm{~cm}$ was found in $54(54.0 \%)$ patients and closed was found in $44(44.0 \%)$ patients. Uterus size was 8 weeks in $34(34.0 \%)$. The following table is given below in detail:

Table-3: Distribution of the study patients according to per vaginal examination findings $(\mathbf{n}=100)$

\begin{tabular}{|c|c|c|}
\hline Per-vaginal findings & Number of patients & Percentage \\
\hline OS $(\mathrm{cm})$ & & \\
\hline 1.5 & 54 & 54.0 \\
\hline 2 & 2 & 2.0 \\
\hline Close & 44 & 44.0 \\
\hline UT (weeks) & & \\
\hline 6 & 24 & 24.0 \\
\hline 8 & 34 & 34.0 \\
\hline 10 & 32 & 32.0 \\
\hline 12 & 10 & 10.0 \\
\hline
\end{tabular}

In table-4 shows distribution of the study patients according to induction expulsion interval. In $(50.0 \%)$ of study population the induction expulsion interval was found between 7-12 hours. The mean induction expulsion interval was $10.83 \pm 5.45$ hours with range from 4 to 29 hours. The following table is given below in detail:

Table-4: Distribution of the study patients according to induction expulsion interval $(\mathrm{n}=100)$

\begin{tabular}{|l|c|c|}
\hline Induction expulsion interval (hours) & Number of patients & Percentage \\
\hline$\leq 6$ & 24 & 24.0 \\
\hline $7-12$ & 50 & 50.0 \\
\hline $13-18$ & 15 & 15.0 \\
\hline$>18$ & 11 & 11.0 \\
\hline Mean \pm SD & 10.83 & \pm 5.45 \\
\hline Range (min-max) & $(4$ & $-29)$ \\
\hline
\end{tabular}

In table-5 shows relation between gravida and number of doses required for the study patients. Among primi gravida $4(4.0 \%)$ patients required $1^{\text {st }}$ dose, $10(10.0 \%) 2^{\text {nd }}$ doses, $6(6.0 \%) 3^{\text {rd }}$ doses and $12(12.0 \%)$ in $4^{\text {th }}$ doses. Among multi gravida $22(22.0 \%)$ patients required $1^{\text {st }}$ dose, $20(20.0 \%) 2^{\text {nd }}$ doses, $10(10.0 \%) 3^{\text {rd }}$ doses and $12(12.0 \%)$ in $4^{\text {th }}$ doses. The following table is given below in detail:

Table-5: Relation between gravida and number of doses required for the study patients $(\mathrm{n}=100)$

\begin{tabular}{|l|c|c|c|c|c|c|c|c|}
\hline Gravida & \multicolumn{2}{|c|}{$\begin{array}{c}\mathbf{1}^{\text {st }} \text { dose } \\
(\mathbf{n = 3 0})\end{array}$} & \multicolumn{2}{c|}{$\begin{array}{c}\mathbf{2}^{\text {nd }} \text { dose } \\
(\mathbf{n}=\mathbf{3 0})\end{array}$} & \multicolumn{2}{c|}{$\begin{array}{c}3^{\text {rd }} \text { dose } \\
(\mathbf{n}=\mathbf{1 6})\end{array}$} & \multicolumn{2}{|c|}{$\begin{array}{c}\mathbf{4}^{\text {th }} \text { dose } \\
(\mathbf{n = 2 4})\end{array}$} \\
\hline & $\mathrm{n}$ & $\%$ & $\mathrm{n}$ & $\%$ & $\mathrm{n}$ & $\%$ & $\mathrm{n}$ & $\%$ \\
\hline Primi & 4 & 4.0 & 10 & 10.0 & 6 & 6.0 & 12 & 12.0 \\
\hline Multi & 22 & 22.0 & 20 & 20.0 & 10 & 10.0 & 12 & 12.0 \\
\hline
\end{tabular}

In figure-4 shows side effect of the study patients. No side effect patients was found in $88(88.0 \%)$. Nausea $6(6.0 \%)$, vomiting $4(4.0 \%)$ and cramping 2(2.0\%) of the study patients. The following figure is given below in detail:

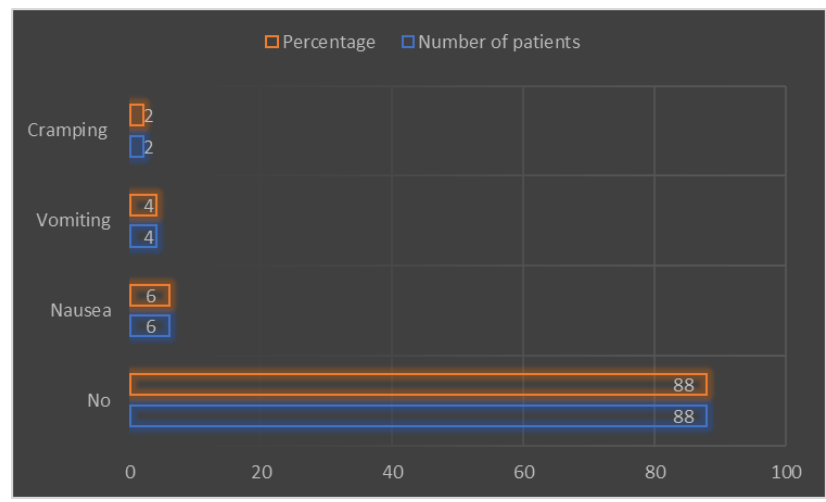

Fig-4: Side effect of the study patients. 
In table-6 shows USG findings after 24 hours. Normal USG was found $88(88.0 \%)$ and retained product was in $12(12.0 \%)$. These 12 patients failed medical management and D \& C done. The following table is given below in detail:

Table-6: USG findings after 24 hours $(n=100)$

\begin{tabular}{|l|c|c|}
\hline USG findings after 24 hours & Number of patients & Percentage \\
\hline Normal & 88 & 88.0 \\
\hline Retained product & 12 & 12.0 \\
\hline
\end{tabular}

In table-7 shows satisfaction level of the study patients. $65 \%$ patients strongly agreed about easy ingestion of the drug $33(33.3 \%)$ agreed and disagree $2(2.0 \%), 5 \%$ of patients strongly agreed of having discomfort after ingestion of the drug, $15 \%$ disagreed, $30 \%$ uncertain. The process was more preferable than surgical procedure $55.0 \%$ strongly agreed, $4.0 \%$ disagreed and about recommendation of this process to other relatives $49.0 \%$ strongly agreed, 42(42.0\%) agreed, $5(5.0 \%)$ uncertain and 4(4.0\%) disagreed. The following table is given below in detail:

Table-7: Patients satisfaction level distribution of the study patients $(n=100)$

\begin{tabular}{|l|c|c|}
\hline Patients satisfaction level & Number of patients & Percentage \\
\hline Ingestion of the drug was easy & 65 & 65.0 \\
\hline Strongly agree & 33 & 33.0 \\
\hline Agree & 0 & 0.0 \\
\hline Uncertain & 2 & 2.0 \\
\hline Disagree & 0 & 0.0 \\
\hline Strongly disagree & & \\
\hline Did you feel any discomfort & 5 & 5.0 \\
\hline Strongly agree & 15 & 15.0 \\
\hline Agree & 30 & 30.0 \\
\hline Uncertain & 44 & 44.0 \\
\hline Disagree & 6 & 6.0 \\
\hline Strongly disagree & & \\
\hline Was the process more preferable than surgical Procedure & 55 & 55.0 \\
\hline Strongly agree & 36 & 36.0 \\
\hline Agree & 5 & 5.0 \\
\hline Uncertain & 4 & 4.0 \\
\hline Disagree & 0 & 0.0 \\
\hline Strongly disagree & & \\
\hline Did you recommend this process to other relatives & 49 & 49.0 \\
\hline Strongly agree & 42 & 42.0 \\
\hline Agree & 5 & 5.0 \\
\hline Uncertain & 4 & 4.0 \\
\hline Disagree & 0 & 0.0 \\
\hline Strongly disagree & & \\
\hline
\end{tabular}

\section{DISCUSSION}

Several studies show, the mean age of the patients were 25.8 years, $25.5 \pm 6.8$ years and $25.8 \pm 6.0$ years respectively, which are closely resembled with the present study[6,7].

One report mentioned that $87.0 \%$ women received one to three doses of misoprostol and in the remaining $13.0 \%$ the regimen was repeated, which is comparable with the current study [10]. One report has shown the median induction expulsion interval was 15.2 hours, which is comparable with the current study [11].

One study result confirms that $400 \mathrm{mcg}$ sublingual misoprostol effectively evacuates the uterus for most women experiencing incomplete abortion. The high level of satisfaction and overall tolerability of the side effects also attests to the ease of use of this method. International momentum and consensus around the drug's utility for this indication has grown stemming in part from misoprostol's inclusion on the WHO's essential medicines list (EML) for this indication [12].

Another study said that $87.5 \%$ were satisfied or very satisfied and $93.8 \%$ would choose this method again in future [13].

Recently, large number of studies is conducted to evaluate the efficacy of mifepristone and misoprostol regime, using different routes in different doses and in different interval for medical termination of early 
pregnancy. For example, misoprostol is used orally, sublingually, buccally in different doses of 200, 400 and $600 \mu \mathrm{g}$ the interval between the drugs are also shortened from 48 hours to 24 hours to 12 hours or even given simultaneously[14,15].

\section{Conclusion}

This study concluded that misoprostol is the potential and effective drug in the medical management of incomplete abortion. Treatment with misoprostol can reduce the demand for surgical evacuation in cases of incomplete abortion.

\section{REFERENCE}

1. Akın A, Dabash R, Dilbaz B, Aktün H, Dursun P, Kıran S, Aksan G, Doğan B, Winikoff B. Increasing women's choices in medical abortion: A study of misoprostol $400 \mu \mathrm{g}$ swallowed immediately or held sublingually following $200 \mathrm{mg}$ mifepristone. The European Journal of Contraception \& Reproductive Health Care. 2009 Jan 1;14(3):169-75.

2. Alan H, Decherney, Lauren, Nathan T, Murphy, Goodwin, Neri, Laufer. Early pregnancy risks, Current diagnosis and treatment, obstetrics and gynaecology, 10th edi; 2007:259.

3. Bagratee JS, Khullar V, Regan L, Moodley J, Kagoro H. A randomized controlled trial comparing medical and expectant management of first trimester miscarriage. Human Reproduction. 2004 Feb 1;19(2):266-71.

4. Bique C, Ustá M, Debora BE, Chong E, Westheimer E, Winikoff B. Comparison of misoprostol and manual vacuum aspiration for the treatment of incomplete abortion. International Journal of Gynecology \& Obstetrics. 2007 Sep;98(3):222-6.

5. Blanchard K, Taneepanichskul S, Kiriwat O, Sirimai K, Svirirojana N, Mavimbela N, Winikoff B. Two regimens of misoprostol for treatment of incomplete abortion. Obstetrics \& Gynecology. 2004 May 1;103(5):860-5.

6. Blum J, Winikoff B, Gemzell- Danielsson K, Ho PC, Schiavon R, Weeks A. Treatment of incomplete abortion and miscarriage with misoprostol. International Journal of Gynecology \& Obstetrics. 2007 Dec;99:S186-9.

7. Cheung T, Leung P, Cheung LP, Haines C, Chang AM. A medical approach to management of spontaneous abortion using misoprostol. Acta Obstet Gynecol Scand. 1997;76:248-51.

8. Chung TK, Lee DT, Cheung LP, Haines CJ, Chang AM. Spontaneous abortion: a randomized, controlled trial comparing surgical evacuation with conservative management using misoprostol. Fertility and sterility. 1999 Jun 1;71(6):1054-9.

9. Coughlin LB, Roberts D, Haddad NG, Long A. Medical management of first trimester incomplete miscarriage using misoprostol. Journal of Obstetrics and Gynaecology. 2004 Jan 1;24(1):678 .

10. Davis AR, Hendlish SK, Westhoff C, Frederick MM, Zhang J, Gilles JM, Barnhart K, Creinin MD, National Institute of Child Health and Human Development Management of Early Pregnancy Failure Trial. Bleeding patterns after misoprostol vs surgical treatment of early pregnancy failure: results from a randomized trial. American journal of obstetrics and gynecology. 2007 Jan 1;196(1):31-e1.

11. Diop A, Raghavan S, Rakotovao JP, Comendant R, Blumenthal PD, Winikoff B. Two routes of administration for misoprostol in the treatment of incomplete abortion: a randomized clinical trial. Contraception. 2009 Jun 1;79(6):456-62.

12. Arias F, Bhide AG, Arulkumaran S, Damania K, Daftary SN, editors. Practical Guide to High Risk Pregnancy and Delivery-E-Book. Elsevier health sciences. 2012 May 14.

13. Graziosi GC, Mol BW, Reuwer PJ, Drogtrop A, Bruinse HW. Misoprostol versus curettage in women with early pregnancy failure after initial expectant management: a randomized trial. Human reproduction. 2004 Aug 1;19(8):1894-9.

14. Newhall EP, Winikoff B. Abortion with mifepristone and misoprostal regime, efficacy, accepted and future direction. Am J Obstet Gynecol. 2001; 83 Suppl 2 S 44-53.

15. Wedisinghe L, Elsandabesee D. Flexible mifepristone and misoprostol administration interval for first-trimester medical termination. Contraception. 2010 Apr 1;81(4):269-74. 